\title{
Information seeking strategies in cognitive development
}

\section{K. ROGER VAN HORN AND WAYNE H. BARTZ, DEPARTMENT OF PSYCHOLOGY, IOWA STATE UNIVERSITY, Ames, Iowa}

The information seeking strategies of six-, seven-, and eight-year old children were investigated in a 20 Questions game. The array of alternatives was presented in random or ordered fashion and chosen alternatives were removed from the array on half the problems. The sixes used informational constraints only with the Ordered array. The sevens and eights established constraints under both conditions.

Bruner (1966) argued that the thinking of young children is largely dependent upon perceptible aspects of the environment. Thus, when a child seeks relevancy or information we might expect his search to be guided by those features which can be "seen" in the situation rather than those which must be abstracted from it. Mosher \& Hornsby (1966) investigated this possibility using the old parlor game of 20 Questions. They found that when faced with a fixed set of alternative solutions to a problem six-year-olds used a strategy in which each alternative was tested individually until the correct one was found. Among the eight- and eleven-year-olds the characteristic strategy consisted of establishing constraints upon the set of alternatives until only the correct one remained tenable. In this situation the appropriate constraints were not perceptually obvious and the youngest children were unable to use them. In a similar situation they found that children did, however, recognize the value of constraint questions before they were able to generate such questions on their own.

The present study was designed to investigate the information seeking strategies of children in a situation where the appropriate constraints either were or were not "suggested by" the nature of the situation. The major hypothesis is that young children are unable to impose order on a perceptually disordered environment. Thus, it was predicted that the ability to establish informational constraints would increase not only with age, but also with the degree to which those constraints could be "seen" in the situation. In addition, the effect of varying the amount of cognitive strain imposed by the task was examined. Finally, some evidence was gathered concerning the child's ability to recognize questions representative of efficient information seeking strategies.

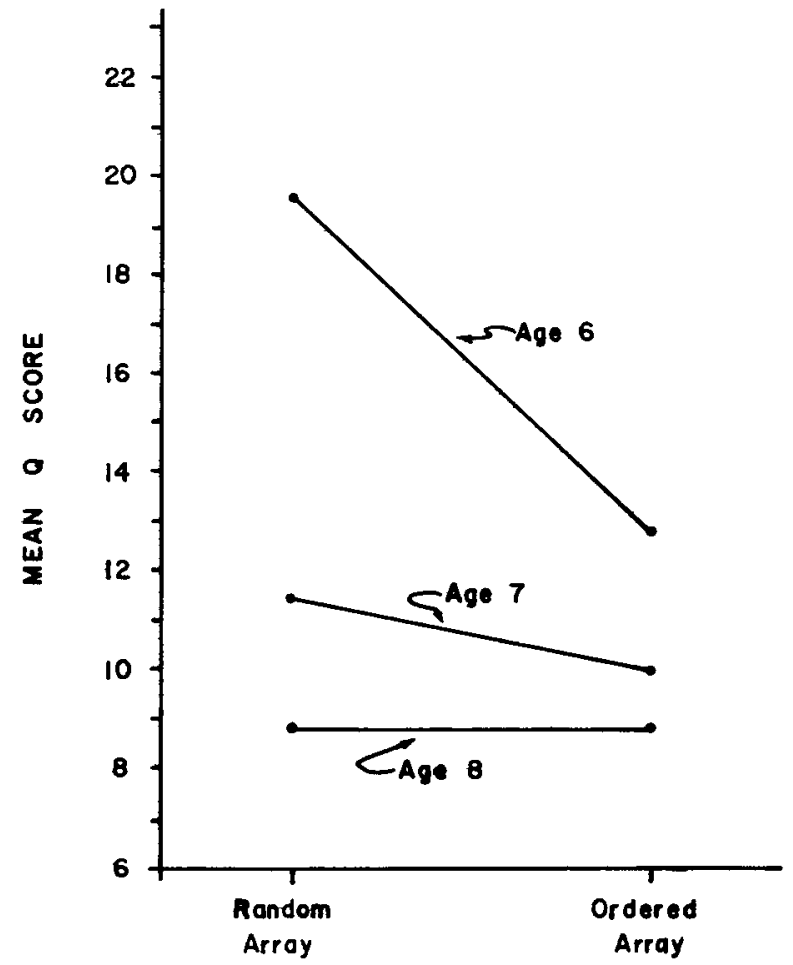

Fig. 1. Mean Q scores for each age under Random and Ordered Array conditions.

Method. Sixteen children were selected from each of grades $\mathbf{k}, 1$, and 2 in local public elementary schools. The only selection criterion was that their teachers judged them to be above average in mental ability. All children were tested individually. The testing sessions were tape recorded and scored at a later time.

Twenty-four line drawings of familiar objects were used. The drawings consisted of three each (one red, one yellow, and one blue) of four different animals and four different toys. The drawings were arranged in an Ordered

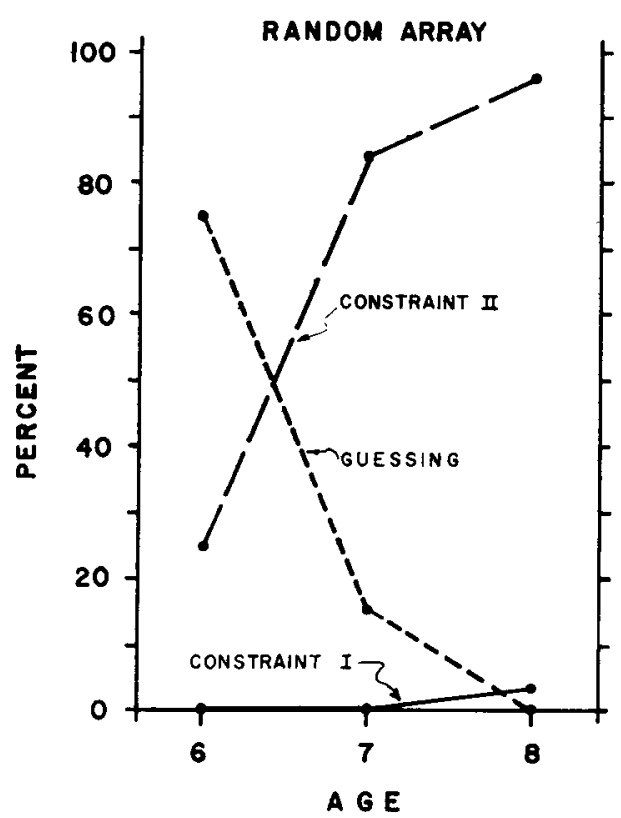

A G E

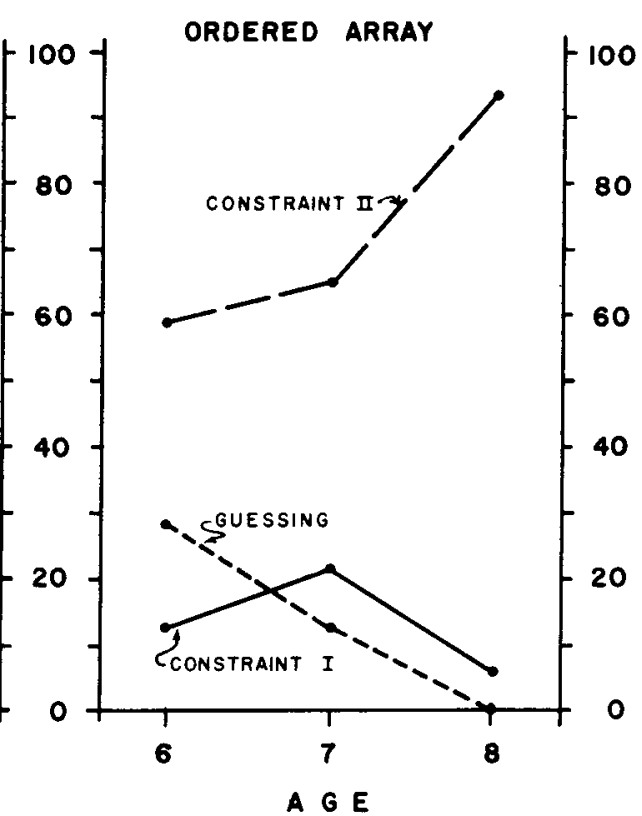

A G E
Fig. 2. Percentage of problems for each age in which each type of strategy was used. 


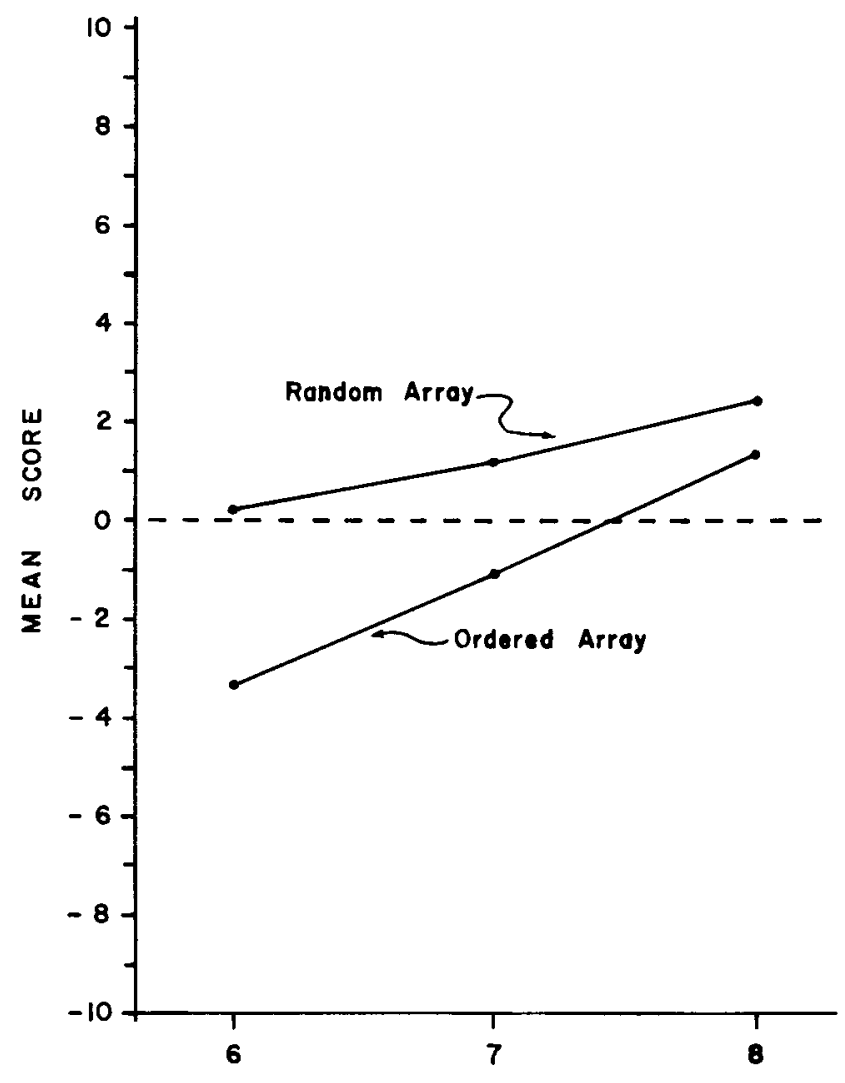

A G E

Fig. 3. Mean information recognition scores for each age following Random and Ondered Array conditions in the 20 Questions problems.

Array for half of the children at each age and a Random Array for the other half. In the Ordered Array a row consisted of the three drawings of one animal or toy, and a column consisted of all drawings that were the same color. The animals were all in the top half of the array and the toys in the bottom half. In the Random Array the position for each drawing was determined randomly.

The child was seated before the array of drawings and asked to name each drawing and indicate what color it was. Then $E$ explained that half of the drawings were animals and the other half toys, and that for each animal or toy there was one red, one yellow, and one blue.

Following this procedure the child was told that the game was for him to find out which drawing $E$ had in mind. To do this he could ask any question that could be answered by E with a simple "yes" or "no." Each child played four games of this type. Half of the children played Games 1 and 2 and the other half played Games 3 and 4 under the condition that drawings eliminated by questions were removed from the array. In the other two games, eliminated alternatives were not removed from the array so that $\mathrm{S}$ had to remember which drawings remained to be checked.

After solving all four problems each child was given a task designed to show his ability to recognize the information value of particular questions. This task consisted of asking the child which of a pair of questions he would rather ask if he were at the beginning of a game like the ones he had just played. Ten pairs were presented in which one member of each pair was informationally more valuable than the other, e.g., "Would you rather ask, "Is it a toy?' or "Is it the red ball?'?" If the child chose the more valuable question he was scored +1 . If he chose the less valuable question he was scored -1 . Consequently, each child's information recognition seore could range from -10 to +10 .

One further aspect of the procedure requires comment. Since the major purpose of this study was to examine children's strategies it was desirable that the Ss ask enough questions in each game to permit valid descriptions of the strategies. Consequently, the "correct" drawing was not determined in advance but was chosen by $\mathrm{E}$ as the game progressed. This procedure has the distinct advantage of ensuring sufficient data to describe every child's strategies while allowing him to use his own strategy. Given this procedure each strategy is described in terms of a minimum number of questions (Q) required to reach a solution without accidentally "stumbling" onto the correct alternative.

The strategy used on each problem by each child was classified as one of three ideal types: (a) Constraint $I$ in which the child used the toy-animal dimension in combination with other appropriate constraints (minimum $Q=$ 6); (b) Constraint II in which questions involved constraints but not the toy-animal dimension (minimum $Q=9$ ); and (c) guessing in which each question was a direct test of only one alternative (minimum $Q=23$ ).

Results. A 3 by 2 by 2 analysis of variance revealed significant Age $(F=10.93, d f=2 / 42, \quad p<.01)$ and Array $(F=4.18$, $\mathrm{df}=1 / 42, \mathrm{p}<.05)$ main effects. The main effect for Removal and all interactions were nonsignificant. The Duncan's New Multiple Range Test applied to the six means shown in Fig. 1 showed all means except the two at age eight to differ significantly from each other $(p=.005)$. Fig. 2 shows the percentage of problems in which each strategy was used at each age. The dominant strategy for six-year-olds under the Random Array condition was Guessing. For all other combinations of Age and Array the dominant strategy was Constraint II.

The information recognition scores by Age and Array are shown in Fig. 3. A 2 by 2 analysis of variance revealed significant main effects for both Age $(\mathrm{F}=3.54$, $\mathrm{df}=2 / 42, \mathrm{p}<.05)$ and Array $(F=4.38$, df $=1 / 42, p<.05)$ and a nonsignificant interaction. At all ages children who had used the Ordered Array tended to choose informationally less valuable questions than those who had the Random Array. In general, the group means were not different from zero-the "chance" level.

Discussion. The results of this study strongly suggest that what the young child lacks is an ability to impose order on a perceptually disordered environment, as was predicted by the major hypothesis. Most of the six-year-olds were able to establish constraints upon the set of alternative solutions, but only under the Ordered Array condition where the constraints were suggested by the nature of the Array. With the Random Array, the six-year-olds' strategies generally consisted of direct tests of single alternatives. Among both the seven- and eight-year-olds the characteristic strategy, regardless of the nature of the array, consisted of locating informational constraints which eventually eliminated all except the single correct alternative.

The removal of eliminated alternatives had no effect on the children's strategies. Since the game was a relatively simple one. the reduction in cognitive strain due to this manipulation was too small to have any effect. This manipulation, however, might prove significant in problems of greater difficulty.

Little evidence was found to support the hypothesis that children could recognize questions representative of efficient strategies. In fact, the data on information recognition suggest that the $S s$ in this experiment were less able to recognize efficient strategies than they were to generate them. However, the results do suggest that the experience of establishing constraints in the Random Array condition aided in the recognition of informative questions. This was particularly the case for the six-and seven-year-old children.

\section{REFERENCES}

BRUNER, J. S. On cognitive growth. In J. S. Bruner, Rose R. Olver, Patricia M. Greenfield et al (Eds.). Studies in cognitive growth. New York: Wiley, 1966. Pp. 1-29.

EDWARDS, A. L. Experimental design in psychological research. New York: Holt. Rinchart, and Winston, 1950.

MOSHI:R, F. A., \& HORNSBY. J. R. On asking questions. In J. S. Bruner, Rose R. Olver. Patricia M. (ireenfield et al (Eds.), Studies in cognitive growth. New York: Wiley, 1966. Pp. 86-102. 